\title{
The examination of quality of pregnancy care based on the World Health Organization's "Responsiveness" model of selected pregnant women in Tehran
}

\author{
Tahereh Marhamati ${ }^{1}$, Shahnaz Torkzahrani ${ }^{2}$, Malihe Nasiri $^{3}$, Razieh Lotfi $^{4}$
}

${ }^{1}$ M.Sc. of Midwifery, School of Nursing and Midwifery, Shahid Beheshti University of Medical Sciences, International Branch, Tehran, Iran

${ }^{2}$ M.Sc. of Midwifery, School of Nursing and Midwifery, Shahid Beheshti University of Medical Sciences, Tehran, Iran

${ }^{3}$ Ph.D. in Biostatistics, Assistant Professor, Faculty of Nursing and Midwifery, Shahid Beheshti University of Medical Sciences, Tehran, Iran

${ }^{4}$ Assistant Professor, Department of Midwifery, School of Nursing and Midwifery, Alborz University of Medical Sciences, Karaj, Iran

\section{Type of article: Original}

\begin{abstract}
Introduction: The World Health Organization (WHO) Responsiveness model showing the ability of health systems in fulfilling people's expectations in connection with nonclinical aspects is an appropriate pattern to assess healthcare. The purpose of this study was to determine the status of pregnancy care provisions based on the responsiveness model.

Methods: This was a cross-sectional study conducted by randomly sampling 130 women visiting selected hospitals in Tehran in 2015. A researcher-made questionnaire based on the responsiveness model of WHO was used to collect data. We determined the face validity and content validity of the questionnaire, and its reliability was confirmed by Cronbach's alpha coefficient $(0.94)$ and test-retest analysis $(0.96)$. The obtained data were analyzed by SPSS version 20 descriptive statistics, t-test, one-way ANOVA, Pearson product-moment correlation coefficient, and Spearman correlation.

Results: Total responsiveness from the perspective of service recipients was $69.46 \pm 14.65$ from 100 . The obtained scores showed that, in the range of 0 to $100,73.02$ were about basic amenities (the most score), 72.93 about dignity, 70.91 about communication, 70.76 about confidentiality, 66.30 about provision social needs, 65.96 about choice of provider, 65.92 about autonomy, and 52.65 about prompt attention (the lowest score), which are representing the average level of service quality. There were significant relationships between participating in preparation class of labor and dignity $(\mathrm{p}<0.001)$, autonomy $(\mathrm{p}=0.01)$, provision social needs $(\mathrm{p}=0.01)$, and overall responsiveness $(\mathrm{p}=0.03)$. It was obtained that there is a significant linear relationship between scores given to hospitals and dimensions of responsiveness $(\mathrm{p}=0.05)$. Findings indicated a significant relationship between insurance type and dimensions of choice of provider $(\mathrm{p}=0.03)$ and communication $(\mathrm{p}=0.03)$.

Conclusion: The mean score of service quality in the present investigation illustrated that nonclinical dimensions have been disregarded and it has potential to be better. So some grand plans are needed.

Keywords: Quality, Responsiveness, Pregnancy care
\end{abstract}

\section{Introduction}

The main incentive for all efforts and developments in human societies is to improve and maintain human health (1). The health of the general population depends on improving the health of pregnant women and infants (2). Every year there are 132 million births in the world (3), providing high-quality and suitable services to maternal satisfaction and improving their health status plays a leading role in health systems (4). Access to high-quality services in the area of pregnancy health is being considered as a right of people, and governments have a

\section{Corresponding author:}

Shahnaz Torkzahrani, School of Nursing and Midwifery, Shahid Beheshti University of Medical Sciences, Tehran, Iran. Tel: +98.2188202512, Fax: +98.2188202512, Email: zahranishahnaz@yahoo.com

Received: June 18, 2016, Accepted: September 19, 2016, Published: February 2017

iThenticate screening: August 29, 2016, English editing: October 21, 2016, Quality control: December 04, 2016

(C) 2017 The Authors. This is an open access article under the terms of the Creative Commons Attribution-NonCommercialNoDerivs License, which permits use and distribution in any medium, provided the original work is properly cited, the use is non-commercial and no modifications or adaptations are made. 
commitment to provide it (5). There are many definitions of quality of pregnancy health services, but all of them have a point in common: that good quality of services need educated staff providing services with respect in an appropriate place for applicants (6). Quality maternal care is referred care that is appropriate, satisfactory, affordable, and easily accessible and enables one to make healthy lifestyle choices (7). Quality of care can be measured in two dimensions: first, the way of providing care technically; second, experiences of care users that are of great importance in evaluating services (8). In fact, customer expectations are beliefs in the assessment of health provisions that are employed as a point of reference and standards to exactly make sense of service quality (9). Depending on what Redshaw has stated, allowing for women to express their perspectives at different stages of receiving care, a variety of sites and providers have built an accurate picture of received care (10). Negative experience of pregnant women when receiving care may have an adverse impact on them (11). The studies have shown that poor quality of care leads to the occurrence of disease, more disabilities, higher cost (12), and less use of care by women $(13,14)$. Generally, clients being satisfied continue to use and encourage others to use services $(15)$. The recognition of customer expectations helps identify priorities of quality improvement (16). The World Health Organization (WHO) presented the concept of "responsiveness," so that it could corroborate a patient's expectations in the standard and combining form. Responsiveness as a special concept in the health system deals with how to provide services and only nonclinical aspects of care. This concept, based on the Donabedian quality framework, shows the ability of health systems in fulfilling people's expectations in connection with nonclinical aspects of them. Taking responsiveness for patient wants along with health improvement and equitable financing is of main goals of WHO (1). Hence, at the international level, health systems make attempts to better their own responsiveness for patients and people (17). Responsiveness makes up eight dimensions, including dignity, autonomy, confidentiality, communication, prompt attention, provision social-needs, basic amenities, choice of provider (1). The WHO, based on experience of patients in 79 European countries, has used this model to the assessment of satisfaction with health systems (18). Wisniewski illustrated that the expectations of patients are higher than their perceptions, there having been space for the betterment of patient satisfaction and providing desirable healthcare (19). Pregnant women need to receive high-quality care. Good quality of care requires that healthcare workers obtain the necessary skills and give serious considerations to the needs of pregnant women. Healthcare organizations require essential equipment and furthermore, referral centers should be efficient when they provide healthcare for the treatment of pregnancy and labor Complications. Women need to receive maternal health services easily. These issues are not feasible except by supervision and assessment of related units as well as attention to service measurement and improvement $(8,20)$. With regard to customer's contribution in healthcare and the advent of total quality management as an approach to quality improvement, health organizations and policymakers have to recognize what health customers think so that they can improve quality of maternal child health services. Because there is no study on provided maternal health services based on the responsiveness model in Iran, the aim of the present study was to investigate quality of maternal child health services based on the responsiveness model of WHO in selected Tehran hospitals in 2015.

\section{Material and Methods}

\subsection{Research design and sampling}

This is a cross-sectional study conducted on women visiting hospitals in Tehran in 2015. Thus, two hospitals affiliated with each of Tehran University of Medical Sciences, Iran University of Medical Sciences, and Shahid Beheshti University of Medical Sciences and one hospital belonging to Bagiyat Allah University were selected randomly. Sampling in each hospital was done based on its quota from the total number of women visited. Totally, 130 qualified pregnant women were selected by convenience sampling method.

\subsection{Selection criteria}

The inclusion criteria consisted of having interest in participating in the study, being a resident in Tehran, having the ability to write and read, and being between 37 and 41 weeks of pregnancy. Exclusion criteria included being an unwilling participate in the study.

\subsection{Ethics, measurement tool, and data collection}

After obtaining written informed consent from women, the questionnaires were filled by themselves. A questionnaire containing demographic and obstetric information and a researcher-made questionnaire based on the responsiveness model of WHO were used to collect data. The questionnaire included 37 items on dignity (eight items), autonomy (five questions), confidentiality (one question), communication (four questions), prompt attention (four questions), provision social-needs (five questions), basic amenities (seven questions), and choice of provider (three questions). The format of questionnaire's questions was a 5-point Likert scale (where $1=$ completely disagree 
and 5 =completely agree). Content validity of questionnaire was examined and confirmed by 10 specialists and face validity confirmed by 30 pregnant women after applying their point of view. Reliability of the questionnaire was checked and confirmed by internal consistency (Cronbach's alpha) based on 30 samples of interest for each element and entire questionnaire (Total alpha $=0.94$ ) and test-retest reliability (a comparison of the results of the questionnaire in the same condition conducted on 30 pregnant women after 10 days from initial tests passed) was conducted and intra-class correlation was 0.96. To study the perspective of pregnant women on satisfaction with the care, pregnant women were asked to score on a scale from 0 to 20 for every hospital in regards to satisfaction with maternal care during the period of pregnancy.

\subsection{Statistical analysis}

The obtained data were analyzed by IBM(C) SPSS(C) Statistics version 20 (IBMC Corp., Armonk, NY, USA). To describe the data, measures of central tendency and dispersion were used. To examine the relationship between demographic variables and dimensions of the questionnaire, after ensuring that they are normally distributed, Kolmogorov-Smirnov test, ANOVA, t-test, and Pearson's correlation (for quantitative data) and Spearman correlation (for ordinal data) were used.

\section{Results}

The mean age of pregnant women was $28.7 \pm 4.9$ and $96.9 \%$ of them were covered by insurance. The mean score given to the hospital was $17.04 \pm 2.4$ from a score of 20 . According to the statements of $91.5 \%$ of pregnant women, if they become pregnant for second time, they return to the same hospital. Table 1 shows the demographic and obstetric features of the samples. There were no significant relationships among age, education, employment, planned pregnancy, rank of pregnancy, and dimension of responsiveness $(\mathrm{p}>0.05)$.

Table 1. Demographic and obstetric variable

\begin{tabular}{|c|c|c|c|}
\hline \multicolumn{2}{|l|}{ variable } & $\mathrm{n}$ & $\%$ \\
\hline \multirow[t]{2}{*}{ Age (year) } & $<30$ & 85 & 65.4 \\
\hline & $>30$ & 45 & 34.6 \\
\hline \multirow[t]{4}{*}{ Education level } & Elementary & 12 & 9.2 \\
\hline & Middle school & 16 & 12.3 \\
\hline & High school & 52 & 40 \\
\hline & Academic & 50 & 38.5 \\
\hline \multirow[t]{2}{*}{ Employment status } & Housekeeper & 113 & 86.9 \\
\hline & Employed & 17 & 13.1 \\
\hline \multirow[t]{4}{*}{ Income (Rial) } & $<10000000$ & 53 & 40.8 \\
\hline & $10000000-15000000$ & 57 & 42.8 \\
\hline & $16000000-20000000$ & 15 & 11.5 \\
\hline & $>2000000$ & 5 & 3.8 \\
\hline \multirow[t]{3}{*}{ Housing } & Self & 41 & 31.5 \\
\hline & Rental & 73 & 56.1 \\
\hline & Relative home & 16 & 12.3 \\
\hline \multirow[t]{2}{*}{ Wanted or unwanted pregnancy } & Wanted & 113 & 86.9 \\
\hline & Unwanted & 17 & 13.1 \\
\hline \multirow[t]{3}{*}{ Fetal gender } & Girl & 70 & 53.8 \\
\hline & Son & 57 & 43.8 \\
\hline & Twin & 3 & 2.3 \\
\hline \multirow[t]{4}{*}{ Rank of pregnancy } & First & 68 & 52.3 \\
\hline & Second & 40 & 30.8 \\
\hline & Third & 19 & 14.6 \\
\hline & Fourth and more & 13 & 2.3 \\
\hline \multirow[t]{4}{*}{ Insurance type } & Social security & 73 & 56.2 \\
\hline & Medical services & 30 & 23.1 \\
\hline & Armed forces & 23 & 17.7 \\
\hline & Without & 4 & 3.1 \\
\hline \multirow[t]{2}{*}{ Participating in preparation class for labor } & Yes & 37 & 28.5 \\
\hline & No & 93 & 71.5 \\
\hline
\end{tabular}


Findings related to the determination of the quality of pregnancy care suggested that scores of total responsiveness of service recipients were $69.46 \pm 14.65$ in the range of 0 to 100 (Table 2). The obtained scores of different dimensions showed that, in the range of 0 to $100,73.02$ were about basic amenities (the most score), 72.93 about dignity, 70.91 about communication, 70.76 about confidentiality, 66.30 about provision social-needs, 65.96 about choice of provider, 65.92 about autonomy, and 52.65 about prompt attention, which are representing the average level of service quality. If we consider the tendency to return the same hospital as a sign of maternal satisfaction from pregnancy care, it is possible to express that whereas satisfaction from services is high, but service quality is at the middle level. Findings obtained utilizing one-way ANOVA suggested a significant relationship between insurance type and dimensions of choice of provider $(p=0.03)$ and communication $(p=0.03)$ (Table 3$)$. The associations between participating in preparation classes of labor and each of the responsiveness dimensions have shown significant relationships between participating in preparation class of labor and dignity $(\mathrm{p}<0.001)$, autonomy $(\mathrm{p}=0.01)$, provision social needs $(\mathrm{p}=0.01)$, and overall responsiveness $(\mathrm{p}=0.03)$ (Table 4$)$. Those participating in the classes gave high scores for all dimensions except for basic amenities. Finally, the Pearson correlation test for determining correlation between scores given to hospitals (in the range of 0 to 20) and dimensions of responsiveness showed no significant relationship between scores and dimensions of responsiveness (Table 5).

Table 2. Score of service quality in total and different dimension of responsiveness

\begin{tabular}{|l|l|l|l|l|}
\hline Variable & Mean & SD & Max & Min \\
\hline Choice of provider & 65.96 & 21.74 & 100 & 0 \\
\hline Communication & 70.91 & 20.06 & 100 & 12.50 \\
\hline Basic amenities & 73.02 & 17.29 & 100 & 35.71 \\
\hline Provision social-needs & 66.30 & 17.52 & 100 & 25 \\
\hline Prompt attention & 65.52 & 18.56 & 100 & 12.50 \\
\hline Confidentiality & 70.76 & 24.13 & 100 & 0 \\
\hline Autonomy & 65.92 & 20 & 100 & 0 \\
\hline Dignity & 72.93 & 16.59 & 100 & 25 \\
\hline Total & 69.46 & 14.65 & 100 & 22.97 \\
\hline
\end{tabular}

Table 3. Association between insurance type and the dimension of responsiveness

\begin{tabular}{|c|c|c|c|c|c|c|c|c|c|}
\hline \multirow[t]{2}{*}{ Variable } & \begin{tabular}{|l|} 
Choice \\
of \\
provider
\end{tabular} & Communication & $\begin{array}{l}\text { Basic } \\
\text { amenities }\end{array}$ & \begin{tabular}{|l|} 
Provision \\
social- \\
needs
\end{tabular} & $\begin{array}{l}\text { Prompt } \\
\text { attention }\end{array}$ & Confidentiality & Autonomy & Dignity & Total \\
\hline & $\begin{array}{l}\text { Mean } \\
\text { (SD) }\end{array}$ & Mean (SD) & $\begin{array}{l}\text { Mean } \\
\text { (SD) }\end{array}$ & $\begin{array}{l}\text { Mean } \\
\text { (SD) }\end{array}$ & $\begin{array}{l}\text { Mean } \\
\text { (SD) }\end{array}$ & Mea & $\begin{array}{l}\text { Mean } \\
\text { (SD) }\end{array}$ & $\begin{array}{l}\text { Mean } \\
\text { (SD) }\end{array}$ & $\begin{array}{l}\text { Mean } \\
(\mathrm{SD})\end{array}$ \\
\hline $\begin{array}{l}\text { Social } \\
\text { security }\end{array}$ & $\begin{array}{l}63.92 \\
(22.48)\end{array}$ & 67.7 & $\begin{array}{l}72.26 \\
(17.05)\end{array}$ & $\begin{array}{l}66.09 \\
(17.68)\end{array}$ & $\begin{array}{l}66.26 \\
(18.74)\end{array}$ & 69. & $\begin{array}{l}63.90 \\
(21.89)\end{array}$ & $\begin{array}{l}71.70 \\
(17.40)\end{array}$ & $\begin{array}{l}68.30 \\
(15.42)\end{array}$ \\
\hline \begin{tabular}{|l|} 
Medical \\
services
\end{tabular} & \begin{tabular}{|l|}
61.38 \\
$(20.11)$ \\
\end{tabular} & 72.9 & $\begin{array}{l}73.09 \\
(19.12) \\
\end{array}$ & $\begin{array}{l}67.00 \\
(16.89) \\
\end{array}$ & $\begin{array}{l}62.91 \\
(18.78) \\
\end{array}$ & 75.0 & $\begin{array}{l}66.00 \\
(16.92) \\
\end{array}$ & $\begin{array}{l}71.77 \\
(17.04) \\
\end{array}$ & \begin{tabular}{|l|}
69.00 \\
$(14.23)$ \\
\end{tabular} \\
\hline $\begin{array}{l}\text { Armed } \\
\text { forces }\end{array}$ & \begin{tabular}{|l|}
77.53 \\
$(15.37)$
\end{tabular} & 74.18 & $\begin{array}{l}73.13 \\
(15.52) \\
\end{array}$ & $\begin{array}{l}66.30 \\
(17.40)\end{array}$ & $\begin{array}{l}67.39 \\
(18.55)\end{array}$ & 67.39 & $\begin{array}{l}70.65 \\
(17.53)\end{array}$ & $\begin{array}{l}75.40 \\
(12.72)\end{array}$ & $\begin{array}{l}72.06 \\
(12.97)\end{array}$ \\
\hline Without & \begin{tabular}{|l|}
70.83 \\
$(34.35)$
\end{tabular} & $95.31(5.98)$ & $\begin{array}{l}85.71 \\
(18.67)\end{array}$ & $\begin{array}{l}65.00 \\
(26.77)\end{array}$ & $\begin{array}{l}60.93 \\
(17.95)\end{array}$ & 75.00 & $\begin{array}{l}75.00 \\
(17.32)\end{array}$ & $\begin{array}{l}89.06 \\
(10.30)\end{array}$ & $\begin{array}{l}79.05 \\
(11.15)\end{array}$ \\
\hline Total & $\begin{array}{l}65.96 \\
(21.74)\end{array}$ & $70.91(20.06)$ & $\begin{array}{l}73.02 \\
(17.29)\end{array}$ & $\begin{array}{l}66.30 \\
(17.52)\end{array}$ & $\begin{array}{l}65.52 \\
(18.56)\end{array}$ & $70.76(2413)$ & $\begin{array}{l}65.92 \\
(20.00)\end{array}$ & $\begin{array}{l}72.93 \\
(16.59)\end{array}$ & $\begin{array}{l}69.46 \\
(14.65)\end{array}$ \\
\hline dilue & 2 & 0.032 & .518 & 0.994 & 0.761 & 0.665 & 0.419 & 0.187 & 0.40 \\
\hline
\end{tabular}


Table 4. Relationship between participating in preparation classes for pregnancy and dimensions of responsiveness

\begin{tabular}{|c|c|c|c|c|c|c|c|c|c|}
\hline \multirow[t]{2}{*}{$\begin{array}{l}\text { Participating } \\
\text { in class }\end{array}$} & \begin{tabular}{|l|}
$\begin{array}{l}\text { Choice } \\
\text { of } \\
\text { provider }\end{array}$ \\
\end{tabular} & Communication & $\begin{array}{l}\text { Basic } \\
\text { amenities }\end{array}$ & \begin{tabular}{|l|} 
Provision \\
social- \\
needs
\end{tabular} & $\begin{array}{l}\text { Prompt } \\
\text { attention }\end{array}$ & Confidentiality & Autonomy & Dignity & Total \\
\hline & $\begin{array}{l}\text { Mean } \\
\text { (SD) }\end{array}$ & Mean (SD) & $\begin{array}{l}\text { Mean } \\
\text { (SD) }\end{array}$ & $\begin{array}{l}\text { Mean } \\
(\mathrm{SD})\end{array}$ & $\begin{array}{l}\text { Mean } \\
(\mathrm{SD})\end{array}$ & Mean (SD) & \begin{tabular}{|l} 
Mean \\
(SD)
\end{tabular} & $\begin{array}{l}\text { Mean } \\
\text { (SD) }\end{array}$ & $\begin{array}{l}\text { Mean } \\
(\mathrm{SD})\end{array}$ \\
\hline Yes & $\begin{array}{l}69.14 \\
(22.21)\end{array}$ & 75.16 & $\begin{array}{l}72.68 \\
(18.31)\end{array}$ & $\begin{array}{l}72.43 \\
(16.44)\end{array}$ & $\begin{array}{l}69.08 \\
(17.61)\end{array}$ & 74.32 & \begin{tabular}{|l|}
72.83 \\
$(17.85)$
\end{tabular} & $\begin{array}{l}78.96 \\
(14.81)\end{array}$ & $\begin{array}{l}73.66 \\
(14.24)\end{array}$ \\
\hline No & $\begin{array}{l}64.69 \\
(21.54)\end{array}$ & 69.22 & $\begin{array}{l}73.15 \\
(16.97)\end{array}$ & $\begin{array}{l}63.87 \\
(17.43)\end{array}$ & $\begin{array}{l}64.11 \\
(18.83)\end{array}$ & 69.35 & $\begin{array}{l}63.17 \\
(20.24)\end{array}$ & $\begin{array}{l}70.53 \\
(16.72)\end{array}$ & $\begin{array}{l}67.79 \\
(14.55)\end{array}$ \\
\hline$p$-value & 0.294 & 0.128 & 0.889 & 0.011 & 0.169 & 0.219 & 0.012 & 0.008 & 0.039 \\
\hline
\end{tabular}

Table 5. Correlation between scores given to hospitals and dimensions of responsiveness

\begin{tabular}{|l|l|l|l|l|l|l|l|l|l|}
\hline Statistics & $\begin{array}{l}\text { Choice } \\
\text { of } \\
\text { provider }\end{array}$ & Communication & $\begin{array}{l}\text { Basic } \\
\text { amenities }\end{array}$ & $\begin{array}{l}\text { Provision } \\
\text { social- } \\
\text { needs }\end{array}$ & $\begin{array}{l}\text { Prompt } \\
\text { attention }\end{array}$ & Confidentiality & Autonomy & Dignity & Total \\
\hline r & 0.45 & 0.44 & 0.35 & 0.34 & 0.51 & 0.43 & 0.55 & 0.52 & 0.57 \\
\hline p-value & $<0.001$ & $<0.001$ & $<0.001$ & $<0.001$ & $<0.001$ & $<0.001$ & $<0.001$ & $<0.001$ & $<0.001$ \\
\hline
\end{tabular}

\section{Discussion}

The purpose of this study is to assess the performance of responsiveness of obstetric services provided for pregnant women in Tehran. Findings suggested that the mean of total responsiveness scores was 69.64 from 100 showing average level of responsiveness. The best and poorest performances in terms of responsiveness were dimensions of basic amenities and prompt attention, respectively, which indicate a positive perspective of pregnant women on quality of settings providing services. On the other hand, negative perspective of them implies dimensions of prompt attention, failure in urgently providing vital services and long waiting time. In a study by Ameriuon et al. in military hospitals of Tehran in 2014, the mean and standard deviation of total responsiveness scores were $97 \pm 7.5$ from 160 , representing upper middle mean of responsiveness score, which has concordance with the results of this study (21). In a study by Gharaee and associations on government hospitals, private and charity hospitals of Hamedan and Yazd provinces, which is conducted in 2013, all dimensions of autonomy, basic amenities, confidentiality of information and having the right to select were assessed as average level and participants gave high scores to dimensions of dignity, communication, prompt attention and provision social-needs in both cities (22). The study of Gromulska et al. entitled "Responsiveness to the hospital patient needs in Poland" recommended that total responsiveness score was $73 \%$ and scores of other dimensions were respectively, from much to less, $96 \%$ for provision social-needs, $92 \%$ for dignity, $85 \%$ for communication, $76 \%$ for autonomy, $70 \%$ for prompt attention, $64 \%$ for confidentiality, and $41 \%$ for choice of provider. This study illustrated that outpatient needs had been satisfied in dimensions of provision social-needs, dignity and communication (23). Responsiveness of health system for patients suffering from heart failure in Tehran examined by Karami et al. showed that total responsiveness score is $84 \%$. In this study $66.5 \%$ of outpatients and $57.2 \%$ of inpatients stated that responsiveness is good. The highest scores had given by outpatients and inpatients to dimensions of confidentiality and dignity (24). Health system responsiveness for delivery care in Southern Thailand, by Liabsuetrakul in Thailand, showed that there has been a little difference between dimensions of responsiveness and the lowest score was related to the choice of provider. In this study, type of hospital had significant relationship with all of responsiveness dimensions and insurance type had significant association with dimensions of dignity, choice of provider, prompt attention. The relationships between the rank of pregnancy and provision social-needs, choice of provider, prompt attention and confidentiality were significant (25). In the study of patient experiences and responsiveness of health system in South Africa conducted by Peltzer, the lowest scores that outpatients and inpatients dedicated to aforementioned dimensions were related to waiting time and choice of provider respectively. The percentages of people having given high or very high score were lower in general health centers. $8.16 \%$ of patients admitted to public centers had given scores that were bad or very bad, while only $2.3 \%$ of patients referred to private hospitals gave scores that were bad or very bad (26). According to Bramesfeld, a study about assessing mental health system utilizing responsiveness model in Germany, the best performances obtained in terms of confidentiality and then in dignity dimensions. Outpatients in comparison with inpatients had given the lower scores to responsiveness dimensions (27). In assessing of health system in region of seventeen in Tehran by Rashidian, the best dimensions from the inpatient views were respect and dignity and confidentiality while from outpatient views were dignity and autonomy. The lowest score had been given to basic amenities and autonomy 
dimensions (28). In a study by Mohammadi for assessing responsiveness of health system to outpatients, $58.4 \%$ of outpatients assessed that health system have a good total responsiveness. The best performances were in confidentiality and then communication. The poorest performance belonged to choice of provider. There were relationships between age and dignity, autonomy, choice of provider, and total responsiveness. There were also significant associations between Level of Education and dignity, autonomy, communication and total responsiveness (29). Njeru et al. in a study about assessment of responsiveness tool of WHO in Malindi City located in Kenya, suggested that in the dimension of choice of provider, majority of participants believed that there is no choice to select care unit or providers (30). A study by Ugurluoglu and colleagues in 2006 about responsiveness of health systems from the perspective of managers in Turkey hospitals showed that the highest score (7.27), on a scale of 0$10(0=$ poorest; $10=$ the best $)$, belongs to the dimension of confidentiality. The highest mean scores were dedicated to the dimensions of adherence to dignity and confidentiality during treatment and diagnosis, and the lowest scores to having choice of provider over selecting physicians and healthcare providers (31). Except for dignity in this study and most studies, which is ranked first or second, there were major differences between other dimensions. It appears that differences between the present study and research mentioned above is due to the difference in the research population. Participants in this study were only pregnant women, while in other studies of men, women and patients with chronic diseases, etc. were involved.

The mean score given to hospitals was $17.04 \pm 2.4$ from 20 and $91.5 \%$ of women who stated that they have a tendency to visit the same hospitals in the case of becoming pregnant once again. This matter implies to the positive attitude of women and their satisfaction with services provided. Sawyer and colleagues in a study in 2013 entitled "Parents experiences and satisfaction with care during the birth of their very preterm baby," $80 \%$ of participants were satisfied (32). A study in Nepal by Paudel showed that the satisfaction score in basic amenities was $86 \%$, service provider skills $85 \%$, politeness of staff $83 \%$, waiting time $80 \%$, and participation in decision making $77 \%$, cleanliness $70 \%$, receiving information $69 \%$, and confidentiality $67 \%$, respectively (33). Melese and colleagues in a study in Ethiopia presented that the percentage of women being completely satisfied with labor care is between $4.2 \%$ and $21 \%$ and the lowest scores were in relation to satisfaction with pain management ( $82 \%$ dissatisfaction) (34). Bleich et al. conducted a study entitled "How does satisfaction with the health-care system relate to patient experience" in 21 European countries. They suggested that, in all countries excluding five of them, $50 \%$ of respondents were relatively perfectly satisfied with their own health systems. All dimensions of responsiveness had a significant and positive relationship with satisfaction ( $\mathrm{p}<0.01)$, which is consistent with findings of this study (18).

\section{Conclusions}

Depending on existing evidence, utilizing data obtained from customers to assess and assure quality of healthcare, then the active involvement of customers plays an important role in making policies and improving service quality. Wholly, the mean score of service quality in the present investigation illustrated that nonclinical dimensions have been disregarded, and it has potential to be better without making a huge investment in technology, human resources, and new regulations.

\section{Acknowledgments:}

This article being part of a master student's thesis at the Shahid Beheshti University of Medical Sciences, its code of ethics is IR.SBMU.RAM.REC.1394.500. Hereby, we are grateful to all of authorities positioned in universities of Shahid Beheshti University of Medical Sciences, Tehran University of Medical Sciences, Iran University of Medical Sciences, Bagiyat Allah, and selected hospitals and to the many pregnant women who have attended the study.

\section{Conflict of Interest:}

There is no conflict of interest to be declared.

\section{Authors' contributions:}

All authors contributed to this project and article equally. All authors read and approved the final manuscript.

\section{References:}

1) Murray CJ, Frenk J. A WHO framework for health system performance assessment: Evidence and Information for Policy, World Health Organization. 1999.

2) Organization World Health. Making a difference in countries: strategic approach to improving maternal and newborn survival and health: ensuring skilled care for every birth. 2006.

3) McDevitt, Thomas M. World population profile: US Government Printing Office. 1996. 
4) Srivastava A, Avan BI, Rajbangshi P, Bhattacharyya S. Determinants of women's satisfaction with maternal health care: a review of literature from developing countries. BMC Pregnancy Childbirth. 2015; 15(1): 97. doi: 10.1186/s12884-015-0525-0. PMID: 25928085, PMCID: PMC4417271.

5) De Silva A, Valentine N. A framework for measuring responsiveness. World Health Organization Geneva. 2000.

6) RamaRao S, Mohanam R. The quality of family planning programs: concepts, measurements, interventions, and effects. Stud Fam Plann. 2003; 34(4): 227-48. doi: 10.1111/j.1728-4465.2003.00227.x. PMID: 14758606.

7) Spring S. ACNM quality management in midwifery practice American Collage of Nurse-midwives 1997.

8) Hulton L, Matthews Z, Stones RW. A framework for the evaluation of quality of care in maternity services. 2000 .

9) Zeithaml VA, Berry LL, Parasuraman A. The nature and determinants of customer expectations of service. Journal of the academy of Marketing Science. 1993; 21(1): 1-12. doi: 10.1177/0092070393211001.

10) Redshaw M. Women as consumers of maternity care: measuring "satisfaction" or "dissatisfaction"? Birth. 2008; 35(1): 73-6. doi: 10.1111/j.1523-536X.2007.00215.x. PMID: 18307491.

11) Kish JA. The development of maternal confidence for labor among nulliparous pregnant women. 2003.

12) The challenge \& potential for assuring quality health care for the 21 st century. Washington, DC: [U.S. Dept. of Health and Human Services]: For sale by the U.S. G.P.O, Supt. of Docs, [distributor; 1999. 28 p. p.

13) Rani M, Bonu S, Harvey S. Differentials in the quality of antenatal care in India. Int J Qual Health Care. 2008; 20(1): 62-71. doi: 10.1093/intqhe/mzm052. PMID: 18024998.

14) Karim RM, Abdullah MS, Rahman AM, Alam AM. Identifying influence of perceived quality and satisfaction on the utilization status of the community clinic services; Bangladesh context. Bangladesh Med Res Counc Bull. 2015; 41(1): 1-12. PMID: 27089628.

15) Reerink IH, Sauerborn R. Quality of primary health care in developing countries: recent experiences and future directions. Int J Qual Health Care. 1996; 8(2): 131-9. doi: 10.1093/intqhe/8.2.131. PMID: 8792168.

16) Valentine NB, de Silva A, Kawabata K, Darby C, Murray CJ, Evans DB, et al. Health system responsiveness: concepts, domains and operationalization. Health systems performance assessment: debates, methods and empiricism. 2003; 573-96.

17) Gakidou E, Murray CJ, Frenk J. Measuring preferences on health system performance assessment. Geneva: World Health Organization. 2000.

18) Bleich SN, Özaltin E, Murray CJ. How does satisfaction with the health-care system relate to patient experience? Bulletin of the World Health Organization. 2009; 87(4): 271-8. doi: 10.2471/BLT.07.050401.

19) Wisniewski M, Wisniewski H. Measuring service quality in a hospital colposcopy clinic. Int J Health Care Qual Assur Inc Leadersh Health Serv. 2005; 18(2-3): 217-28. doi: 10.1108/09526860510594776. PMID: 15974517.

20) WHO. Making pregnancy safer: the critical role of the skilled attendant. World Health Organization: Geneva. 2004.

21) Ameriuon A, Jabbarzade Balkanlou M, Tofighi SH, Sepandi M, Ghanjal A. Study the relationship between organizational justice and responsibility dimensions in selected hospitals of the armed forces. Journal of nurse and physician within war. 2014; 25: 23-9.

22) Gharaee H, Bahrami M.A, Hamidi Y, Tapak L, Asqari R. The relationship between organizational climate and responsiveness in Hamedan and yazd selective hospital in 2013. journal of healthcare management. 2011; 3(1-2(7)): 35-47.

23) Gromulska L, Supranowicz P, Wysocki MJ. Responsiveness to the hospital patient needs in Poland. Rocz Panstw Zakl Hig. 2014; 65(2): 155-64. PMID: 25272583.

24) Karami-Tanha F, Moradi-Lakeh M, Fallah-Abadi H, Nojomi M. Health system responsiveness for care of patients with heart failure: evidence form a university hospital. Arch Iran Med. 2014; 17(11): 736-40. doi: 0141711/AIM.003. PMID: 25365611.

25) Liabsuetrakul T, Petmanee P, Sanguanchua S, Oumudee N. Health system responsiveness for delivery care in Southern Thailand. Int J Qual Health Care. 2012; 24(2): 169-75. doi: 10.1093/intqhe/mzr085. PMID: 22215759.

26) Peltzer K. Patient experiences and health system responsiveness in South Africa. BMC Health Serv Res. 2009; 9(1): 117. doi: 10.1186/1472-6963-9-117. PMID: 19602290, PMCID: PMC2716320. 
27) Bramesfeld A, Wedegärtner F, Elgeti H, Bisson S. How does mental health care perform in respect to service users' expectations? Evaluating inpatient and outpatient care in Germany with the WHO responsiveness concept. BMC Health Services Research. 2007; 7(1): 1. doi: 10.1186/1472-6963-7-99.

28) Rashidian A, Kavosi Z, Majdzadeh R, Pourreza A, Pourmalek F, Arab M, et al. Assessing health system responsiveness: a household survey in 17th District of Tehran. Iran Red Crescent Med J. 2011; 13(5): 3028. PMID: 22737485, PMCID: PMC3371967.

29) Mohammadi A, Kamali K. Patients' Perspectives on Responsiveness in Outpatient Clinics of Hospitals at Zanjan University of Medical Sciences. Preventive Care In Nursing \& Midwifery Journal. 2015; 5(1): 8092.

30) Njeru MK, Blystad A, Nyamongo IK, Fylkesnes K. A critical assessment of the WHO responsiveness tool: lessons from voluntary HIV testing and counselling services in Kenya. BMC health services research. 2009; 9(1): 1. doi: 10.1186/1472-6963-9-243.

31) Ugurluoglu O, Celik Y. How responsive Turkish health care system is to its citizens: the views of hospital managers. J Med Syst. 2006; 30(6): 421-8. doi: 10.1007/s10916-005-9006-8. PMID: 17233154.

32) Sawyer A, Rabe H, Abbott J, Gyte G, Duley L, Ayers S. Parents' experiences and satisfaction with care during the birth of their very preterm baby: a qualitative study. BJOG. 2013; 120(5): 637-43. doi: 10.1111/1471-0528.12104. PMID: 23289929, PMCID: PMC3613739.

33) Paudel YR, Mehata S, Paudel D, Dariang M, Aryal KK, Poudel P, et al. Women's Satisfaction of Maternity Care in Nepal and Its Correlation with Intended Future Utilization. International journal of reproductive medicine. 2015; 2015: 9. doi: 10.1155/2015/783050.

34) Melese T, Gebrehiwot $Y$, Bisetegne D, Habte D. Assessment of client satisfaction in labor and delivery services at a maternity referral hospital in Ethiopia. Pan Afr Med J. 2014; 17: 76. doi: 10.11604/pamj.2014.17.76.3189. PMID: 25018826, PMCID: PMC4085898. 